\title{
Recombinant Tumor Necrosis Factor/Cachectin and Interleukin 1 Pretreatment Decreases Lung Oxidized Glutathione Accumulation, Lung Injury, and Mortality in Rats Exposed to Hyperoxia
}

\author{
Carl W. White," Pietro Ghezzi," Charles A. Dinarello," Sherrie A. Caldwell," Ivan F. McMurtry," and John E. Repine* \\ *Departments of Pediatrics, Pathology, Surgery, and Medicine, Webb-Waring Lung Institute, The Children's Hospital, and the University \\ of Colorado Health Sciences Center, Denver, Colorado 80262; ${ }^{\prime}$ Istituto di Ricerche Farmacologiche "Mario Negri", Milan, Italy; ${ }^{\S}$ Tufts \\ University School of Medicine, Division of Geographic Medicine and Infectious Disease, Boston, Massachusetts 02111
}

\begin{abstract}
Single, preexposure, parenteral injection with both recombinant tumor necrosis factor/cachectin (TNF/C) and interleukin-1 (IL1) prolonged the survival of rats $(144 \pm 9 \mathrm{~h})$ in continuous hyperoxia ( $>99 \% \mathrm{O}_{2}$ at $1 \mathrm{~atm}$ ) when compared with rats injected with boiled TNF/C and boiled IL-1 (61 $\pm 2 \mathrm{~h})$, TNF/C alone (61 \pm 2 h), IL-1 alone (62 \pm 2 h), or saline (64 \pm 3 h). After exposure to hyperoxia for $52 \mathrm{~h}$, pleural effusion volume, pulmonary artery pressure, total pulmonary resistance, and lung morphologic damage were decreased in those rats given TNF/C and IL-1 as compared with saline-injected rats. In parallel, ratios of reduced (GSH) to oxidized (GSSG) glutathione were greater $(P<0.05)$ in lungs of TNF/C + IL-1-injected rats $(91 \pm 20)$ than of salineinjected rats $(30 \pm 4)$ that had been exposed to hyperoxia for 52 h. No differences were found in superoxide dismutase, glutathione peroxidase, glutathione reductase, glucose-6-phosphate dehydrogenase, or catalase activities in lungs of TNF/C + IL-1- or saline-treated, hyperoxia-exposed rats. Our results indicate that pretreatment with TNF/C and IL-1 favorably altered lung glutathione redox status, decreased lung injury, and enhanced survival of rats exposed to hyperoxia.
\end{abstract}

\section{Introduction}

Endotoxin pretreatment produces a remarkable protective effect against pulmonary oxygen toxicity, a tolerance that involves decreases in lung and endothelial cell injury that are associated with increases in lung antioxidant enzymes (1). Endotoxin treatment can also stimulate production of two potent cytokines, tumor necrosis factor/cachectin (TNF/C) ${ }^{1}(2)$ and interleukin 1 (IL-1) (3), which may mediate many diverse effects including alterations in endothelial cell growth (4) and function (5). These

Address all correspondence and reprint requests to Dr. Carl W. White, Assistant Professor of Pediatrics, Box C322, 4200 East Ninth Avenue, Denver, CO 80262.

Received for publication 8 October 1986 and in revised form 27 January 1987.

1. Abbreviations used in this paper: GSH, reduced glutathione; GSSG, oxidized glutathione; TNF/C, tumor necrosis factor/cachectin.

J. Clin. Invest.

(c) The American Society for Clinical Investigation, Inc.

0021-9738/87/06/1868/06 \$1.00

Volume 79, June 1987, 1868-1873 findings led us to postulate that treatment with TNF/C and/or IL-1 might affect susceptibility to lung injury from hyperoxia. Also, studies of TNF/C and IL-1 would provide additional new information about the mechanisms of action and the direct or indirect relationships between endotoxin treatment, tolerance to hyperoxia, and lung antioxidant enzyme increases. Our results supported this premise. We found that pretreatment with both TNF/C and IL-1 decreased lung oxidized glutathione content, lung injury, and mortality of rats in hyperoxia without altering lung antioxidant enzyme activities.

\section{Methods}

Reagents. Ferricytochrome $c$ (horse heart, type VI), xanthine, xanthine oxidase (grade III), glucose-6-phosphate dehydrogenase (type IX), $\mathrm{NADP}^{+}$, NADPH (type I), oxidized glutathione (GSSG) (type IV), reduced glutathione (GSH), glutathione reductase (type IV), and glucose6-phosphate were obtained from Sigma Chemical Co., St. Louis, MO. $1,000 \mathrm{U} / \mathrm{ml}$ heparin was supplied by Abbott Laboratories, Diagnostic Div., Irving, TX. Recombinant human TNF/C was provided by Dr. Leo S. Lin (Cetus Corp., Emeryville, CA [6]) and IL-1 $\alpha$ (pI 5) by Dr. Peter T. Lomedico (Hoffmann-La Roche, Inc., Nutley, NJ [7]). Recombinant IL- $1 \beta$ (pI 7) was prepared and purified as previously described (8). Endotoxin contamination was assayed by using Limulus amebocyte lysate assays: TNF/C contained $<66 \mathrm{ng} / \mathrm{mg}$ protein; IL- $1 \alpha,<42 \mathrm{ng} / \mathrm{mg}$ protein; and IL-1 $\beta,<20 \mathrm{ng} / \mathrm{mg}$ protein (8). For some experiments, TNF/C and IL-1 were boiled at $97^{\circ} \mathrm{C}$ for $1 \mathrm{~h}(8)$. Survival studies were done by using IL- $1 \beta$ and then confirmed with IL- $1 \alpha$. IL- $1 \alpha$ was used for subsequent studies.

Treatment with $T N F / C$ and/or IL-1, exposure to hyperoxia, and assessment of survival. Male Sprague-Dawley rats (SASCO, Omaha, NE) weighing 275-300 g were fed a standard laboratory diet of Wayne Lab Blox (Continental Grain Co., Chicago, IL) given water ad lib., and acclimated to Denver altitude for 8-10 d. For most experiments, TNF/C and/or IL-1 were given just before exposure to hyperoxia in split doses ( $50 \%$ i.v. and $50 \%$ i.p.). Before injection, proteins were diluted in 0.15 $\mathrm{M} \mathrm{NaCl}$ buffered with $5 \mathrm{mM}$ potassium phosphate ( $\mathrm{pH} \mathrm{7.4)} \mathrm{that} \mathrm{contained}$ $0.5 \mathrm{mg} / \mathrm{ml}$ bovine serum albumin (Cohn Fraction V, Sigma Chemical Corp.) that had been passed twice over polymyxin B Sepharose columns (3-ml bed vol; Boehringer Mannheim Biochemicals, Indianapolis, IN). For subcutaneous infusion, TNF/C alone was given as a single bolus (5 $\mu \mathrm{g}$ i.p.) and infused $(100 \mu \mathrm{g} / \mathrm{ml})$ continuously through an Alzet miniosmotic pump (Alza Corp., Palo Alto, CA) implanted in the neck (20 $\mu \mathrm{g} / 168 \mathrm{~h}$ ). In all experiments, control rats received equal amounts of saline alone. Rats were continuously exposed to hyperoxia (liquid $\mathrm{O}_{2}$, 10 liters/min) in plexiglas hyperbaric chambers. $\mathrm{O}_{2}$ concentration monitored with an oxygen analyzer (model 0260; Beckman Instruments Inc., Fullerton, CA) was consistently $>99 \%$ (barometric pressure $=760$ $\mathrm{mmHg}$ ), and $\mathrm{CO}_{2}$ concentration was $<0.5 \%$ as measured by a blood gas 
analyzer (Corning Glass Works, Corning Science Products, Corning, NY). Temperature was $23-25^{\circ} \mathrm{C}$; relative humidity, $60-70 \%$; and light exposure, on a 12-h light/dark cycle. Equal numbers of treated and control littermates were exposed in each chamber. The number of living rats was counted every $6 \mathrm{~h}$.

Measurements of cardiopulmonary physiology and morphology. Indwelling pulmonary artery, aortic, and central venous catheters were positioned aseptically $24 \mathrm{~h}$ before exposure (9). After exposure to hyperoxia for $52 \mathrm{~h}$, rats were removed and studied at $\mathrm{FIO}_{2}>99 \%(630$ Torr). Lungs were also obtained, inflated at $20 \mathrm{~cm} \mathrm{H}_{2} \mathrm{O}$ airway pressure, and processed for electron microscopy (10). Pleural fluid was removed into graduated syringes and measured.

Measurement of lung GSH and GSSG contents. After exposure to hyperoxia, anesthesia with pentobarbital $(110 \mathrm{mg} / \mathrm{kg}$, i.p.), tracheostomy, ventilation with $100 \% \mathrm{O}_{2}$, thoracotomy, heparin injection (150 U), exsanguination, and cannulation of the main pulmonary artery and left atrium, rat lungs were flushed with $20 \mathrm{ml}$ of a modified Krebs' Henseleit buffer ( $305 \mathrm{mOsM}$ with $124.5 \mathrm{mM} \mathrm{NaCl}, 3.2 \mathrm{mM} \mathrm{CaCl} 2$ [pH 7.4 at $\left.37^{\circ} \mathrm{C}\right]$ ) that contained $4 \%$ Ficoll 70 (Sigma Chemical Corp.). Blood-free lungs were freeze clamped, weighed, and pulverized under liquid $\mathrm{N}_{2}$. The left lung (GSSG analysis) was homogenized with a Tissu-miser (60 s, maximum speed) (Heat Systems-Ultrasonics, Inc., Farmingdale, NY)

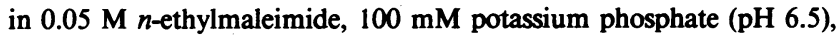
and $5 \mathrm{mM}$ EDTA; the right lung (GSH analysis) was homogenized in $100 \mathrm{mM}$ potassium phosphate (pH 7.5) and $5 \mathrm{mM}$ EDTA. Protein was precipitated with $20 \%$ meta-phosphoric acid $(1: 4, \mathrm{vol} / \mathrm{vol}$ )(Alfa Products, Morton Thiokol Inc., Danvers, MA). After samples were centrifuged at $15,000 \mathrm{~g}$ for $10 \mathrm{~min}$, supernatants were neutralized with $2 \mathrm{M} \mathrm{KOH}$ and $0.3 \mathrm{M}$ 3- $N$-morpholinopropanesulfonic acid, and were prepared and assayed for GSH and GSSG (11).

Measurement of lung antioxidant enzyme activities. After perfusion as described with buffer containing 4\% Ficoll 70, rat lungs were perfused with $5 \mathrm{ml}$ of $0.1 \mathrm{M}$ potassium phosphate, $0.15 \mathrm{M} \mathrm{KCl}$ buffer ( $\mathrm{pH} 7.4$ ), trimmed, rinsed, blotted, and homogenized (right lung) with a Tissumiser $\left(120 \mathrm{~s}\right.$, maximum speed, $\left.4^{\circ} \mathrm{C}\right)$ in a total volume of $10 \mathrm{ml}$ of 0.005 $\mathrm{M}$ potassium phosphate buffer ( $\mathrm{pH} 7.8$ ) that contained 0.1 mM EDTA. After the homogenate was centrifuged $(15,000 \mathrm{~g}$ for $10 \mathrm{~min})$, supernatants were analyzed for total superoxide dismutase (12), glutathione peroxidase (13), glutathione reductase (13), glucose-6-phosphate dehydrogenase (13), and catalase (14) activities.

Statistical analyses. Data from two groups were compared by using a two-tailed $t$ test, and those from more than two groups, by one-way analyses of variance with Student-Newman-Keuls test for multiple comparisons (15). Individual survival curves were constructed (16) and compared nonparametrically with the log rank test (17) in stepwise fashion (18).

\section{Results}

Rats injected before exposure with a single dose of both $10 \mu \mathrm{g}$ TNF/C and $10 \mu \mathrm{g} \mathrm{IL-1}$ lived longer $(P<0.05)$ in continuous hyperoxia ( $144 \pm 9 \mathrm{~h}, n=16)$ than rats injected with both $10 \mu \mathrm{g}$ boiled TNF/C and $10 \mu \mathrm{g}$ boiled IL-1 $(61 \pm 2 \mathrm{~h}, n=9)$ or saline $(64 \pm 3 \mathrm{~h}, n=49$, Fig. $1 A)$. In contrast, rats injected with $10 \mu \mathrm{g}$ TNF/C alone $(61 \pm 2 \mathrm{~h}, n=6)$ or $10 \mu \mathrm{g} \mathrm{IL}-1$ alone $(62 \pm 2 \mathrm{~h}, n$ $=6)$ did not live longer $(P>0.05)$ in hyperoxia than salineinjected rats $(64 \pm 3 \mathrm{~h}, n=49$, Fig. $1 \mathrm{~B})$. Moreover, treatment with $10 \mu \mathrm{g}$ TNF/C and increasing doses of $3.3,10$, or $33 \mu \mathrm{g}$ of IL- 1 was associated with increases in survival $(123 \pm 20 \mathrm{~h}, n=6$; $145 \pm 15 \mathrm{~h}, n=6$; or $150 \pm 6 \mathrm{~h}, n=6$, respectively) of rats in hyperoxia (Fig. $1 C$ ). Furthermore, survival in hyperoxia was similar $(P>0.05)$ in rats that were treated with $10 \mu \mathrm{g} \mathrm{TNF} / \mathrm{C}$ and either $10 \mu \mathrm{g}$ of IL-1 $\beta(143 \pm 12 \mathrm{~h}, n=10)$ or $10 \mu \mathrm{g} \mathrm{IL}-1 \alpha$ $(145 \pm 15 \mathrm{~h}, n=6)$. Finally, treatment with an initial bolus of 5 $\mu \mathrm{g}$ TNF/C alone (i.p.) plus a continuous subcutaneous infusion of $0.12 \mu \mathrm{g} / \mathrm{h}$ of TNF/C alone did not increase $(P>0.05)$ the survival of rats in hyperoxia $(71 \pm 2 h, n=5)$ when compared with saline-treated control rats $(64 \pm 2 \mathrm{~h}, n=5)$.

After exposure to hyperoxia for $52 \mathrm{~h}$, rats injected with TNF/ C and IL-1 also had decreased $(P<0.05)$ pleural effusion volume, hematocrit, pulmonary artery pressure, total pulmonary resistance, and systemic vascular resistance, and increased $(P<0.05)$ cardiac output and arterial $\mathrm{pH}$ as compared with saline-treated rats (Table I). Arterial $\mathrm{PCO}_{2}$ and $\mathrm{PO}_{2}$ were not statistically different $(P>0.05$, Table I). Also, after exposure to hyperoxia for $52 \mathrm{~h}$, lungs from TNF/C + IL-1-treated rats had less vascular congestion and endothelial cell damage as reflected by swelling of endoplasmic reticulum, intracellular edema, and focal disruption than lungs from saline-treated rats (Fig. 2).

Lungs from hyperoxia-exposed rats that had been pretreated with TNF/C and IL-1 had increased GSH/GSSG ratios $(91 \pm 20$ $\mathrm{mol} / \mathrm{mol}, n=6$ ) when compared with simultaneously exposed saline-injected control rats $(30 \pm 4 \mathrm{~mol} / \mathrm{mol}, n=7$, Table I). More specifically, whereas GSSG content was decreased, total GSH content was similar in lungs of TNF/C + IL-1-treated rats as compared with saline-injected rats that had been exposed to hyperoxia for $52 \mathrm{~h}$.

Total lung superoxide dismutase, glutathione peroxidase, glutathione reductase, glucose-6-phosphate dehydrogenase, and

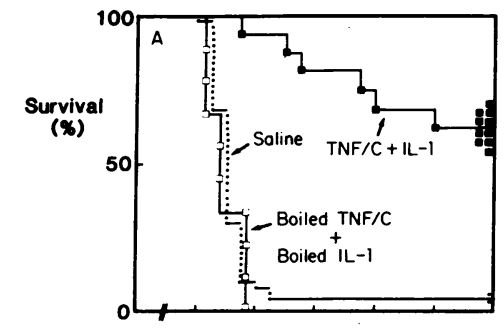

Figure 1. Effect of pretreatment with single doses of TNF/C and/or IL-1 on the duration of survival of rats exposed to continuous hyperoxia (>99\% $\left.\mathrm{O}_{2}, 1 \mathrm{~atm}\right)$. (A) Rats exposed to hyperoxia after pretreatment with $10 \mu \mathrm{g}$ of both TNF/C + IL-1 (口) lived longer than rats treated with $10 \mu \mathrm{g}$ of boiled TNF/C $+10 \mu \mathrm{g}$ boiled IL-1 (), or saline alone (.....). (B) Rats exposed to hyperoxia after pretreatment with $10 \mu \mathrm{g}$ of TNF/C $+10 \mu \mathrm{g} \mathrm{IL-1}$ (a) lived longer than rats treated with $10 \mu \mathrm{g}$ of ei-

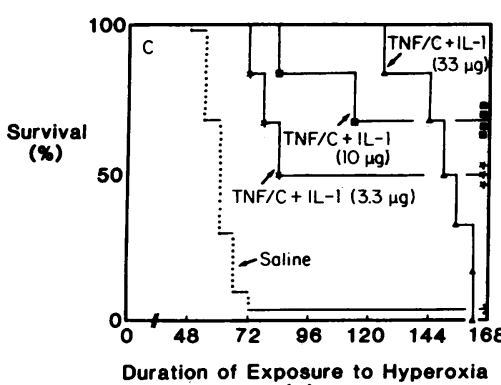

(h) ther TNF/C (O) or IL-1 $(\Delta)$ alone. $(C)$ Rats exposed to hyperoxia after pretreatment with $10 \mu \mathrm{g}$ $\mathrm{TNF} / \mathrm{C}+3.3 \mu \mathrm{g} \mathrm{IL}-1$ (*), $10 \mu \mathrm{g}$ of TNF/C $+10 \mu \mathrm{g}$ IL-1 (घ), or 10 $\mu \mathrm{g}$ TNF/C $+33 \mu \mathrm{g} \mathrm{IL-1}$ (ム) lived longer than rats treated with saline $(\cdots \cdot)$. Each point represents the duration of survival of a single rat. Each rat was given cytokines in a split dose (50\% i.v., 50\% i.p.). Differences in lifespans (longer lives) were established as statistically significant in each case by one-way analyses of variance with Student-Newman-Keuls test $(P$ $<0.05$ ), and by Kaplan-Meier/log rank tests (0.01 significance level). 
Table I. Effect of TNF/C and IL-1 Pretreatment on Cardiopulmonary Physiology and Lung Glutathione Metabolites in Rats Exposed to Hyperoxia

\begin{tabular}{|c|c|c|c|c|}
\hline Pretreatment & Exposure & Pleural effusion volume & Hematocrit & Pulmonary artery pressure \\
\hline & & $m l$ & $\%$ & Torr \\
\hline Saline & Normoxia & $0.0 \pm 0(6)^{* \neq 8}$ & $45 \pm 0.9(9)^{\ddagger}$ & $22 \pm 1(5)^{\ddagger}$ \\
\hline Saline & Hyperoxia & $3.3 \pm 0.6(7)^{\prime \prime}$ & $62 \pm 2(6)^{\prime \prime}$ & $39 \pm 3(6)^{\prime \prime}$ \\
\hline \multirow[t]{3}{*}{ TNF/C + IL-1 } & Hyperoxia & $0.5 \pm 0.2(6)^{\ddagger 11}$ & $45 \pm 0.3(5)^{1 \ddagger}$ & $27 \pm 2(5)^{1 \neq}$ \\
\hline & & Total pulmonary resistance & Cardiac output & Systemic vascular resistance \\
\hline & & $\mathrm{Torr} / \mathrm{ml} / \mathrm{min}$ & $\mathrm{ml} / \mathrm{min}$ & $\mathrm{Torr} / \mathrm{ml} / \mathrm{min}$ \\
\hline Saline & Normoxia & $0.12 \pm 0.01(5)^{\ddagger}$ & $196 \pm 9(5)^{\ddagger}$ & $0.55 \pm 0.05(5)^{\ddagger}$ \\
\hline Saline & Hyperoxia & $0.85 \pm 0.23(6)^{\prime \prime}$ & $95 \pm 22(6)^{\prime \prime}$ & $1.83 \pm 0.44(6)^{\prime \prime}$ \\
\hline \multirow[t]{3}{*}{$\mathrm{TNF} / \mathrm{C}+\mathrm{IL}-1$} & Hyperoxia & $0.18 \pm 0.03(5)^{4 \neq}$ & $168 \pm 18(5)^{1 \ddagger}$ & $0.70 \pm 0.07(5)^{\sharp \ddagger}$ \\
\hline & & Arterial $\mathrm{PCO}_{2}$ & Arterial $\mathrm{PO}_{2}$ & Arterial pH \\
\hline & & Torr & Torr & \\
\hline Saline & Normoxia & $25 \pm 1(3)^{\ddagger}$ & $408 \pm 10(3)^{* *}$ & $7.52 \pm 0.01(3)^{\ddagger}$ \\
\hline Saline & Hyperoxia & $38 \pm 3(6)^{\prime \prime}$ & $284 \pm 59(6)^{\top}$ & $7.36 \pm 0.03(6)^{\|}$ \\
\hline \multirow[t]{3}{*}{$\mathrm{TNF} / \mathrm{C}+\mathrm{IL}-1$} & Hyperoxia & $33 \pm 1(5)^{1 * *}$ & $398 \pm 19(5)^{1 * *}$ & $7.47 \pm 0.01(5)^{9 \neq}$ \\
\hline & & Lung GSH content & Lung GSSG content & Lung GSH/GSSG ratio \\
\hline & & $\mu \mathrm{mol} / \mathrm{two}$ lungs & nmol/two lungs & $\mathrm{mol} / \mathrm{mol}$ \\
\hline Saline & Normoxia & $0.9 \pm 0.1(6)^{\ddagger}$ & $5.6 \pm 0.4(6)^{\ddagger}$ & $157 \pm 11(6)^{\ddagger}$ \\
\hline Saline & Hyperoxia & $1.3 \pm 0.1(7)^{\prime \prime}$ & $46.0 \pm 6(7)^{\prime \prime}$ & $30 \pm 4(7)^{\prime \prime}$ \\
\hline TNF/C + IL-1 & Hyperoxia & $1.2 \pm 0.1(6)^{\| * *}$ & $15.0 \pm 2(6)^{1 \pm}$ & $92 \pm 20(6)^{ \pm 11}$ \\
\hline
\end{tabular}

* Mean \pm 1 SEM (number of determinations). All measurements were made on rats after $52 \mathrm{~h}$ of exposure to hyperoxia $\left(>99 \% \mathrm{O}_{2}, 1 \mathrm{~atm}\right)$.

‡ Value significantly $(P<0.05)$ different from that obtained for saline-pretreated, hyperoxia-exposed rats. ${ }^{\S}$ Saline- or TNF/C + IL-1-injected rats that were exposed to normoxia had similar pleural effusion volume, GSH content, GSSG content, or GSH/GSSG ratios ( $0 \pm 0 \mathrm{ml}, 0.9 \pm 0.1$ $\mu \mathrm{mol} /$ two lungs, $5.1 \pm 0.3 \mathrm{nmol} /$ two lungs, and $178 \pm 17$, respectively, for TNF/C + IL-1-injected, normoxia-exposed rats, $n=6)$. "Value significantly $(P<0.05)$ different from that obtained for saline-pretreated, normoxia-exposed rats. 'Value not significantly different $(P>0.05)$ from that obtained for saline-pretreated, normoxia-exposed rats. ** Value not significantly $(P>0.05)$ different from that obtained for saline-pretreated, hyperoxia-exposed rats.

catalase activities were similar in hyperoxia-exposed rats that were pretreated with TNF/C and IL-1 or saline (Table II).

\section{Discussion}

Preinjection with both TNF/C and IL-1 markedly prolonged the survival of rats in continuous normobaric hyperoxia. Enhanced survival of cytokine-treated rats in hyperoxia was associated with dramatic decreases in lung injury, as manifested by decreased pleural effusion volume, pulmonary hypertension (19), morphologic abnormality (10), and increased lung GSH/GSSG ratio, when compared with values obtained for saline-injected rats. These findings indicate that the TNF/C + IL-1-mediated increase in survival of rats in hyperoxia involved improvement in lung glutathione redox state and decreases in lung injury (20).

Since endotoxin is heat stable (3), whereas cytokine activities are destroyed at temperatures of $97^{\circ} \mathrm{C}$, the finding that injection with boiled cytokines did not increase survival in hyperoxia sug- gests that TNF/C + IL-1-mediated tolerance is not the result of endotoxin contamination (8). Moreover, the amount of endotoxin that contaminated the combined TNF/C $(<0.66 \mathrm{ng} /$ rat) and IL-1 $(<0.42 \mathrm{ng} / \mathrm{rat})$ was $>100,000$-fold less than the endotoxin dose $(\sim 125 \mu \mathrm{g} / \mathrm{rat},[1])$ that produced tolerance to hyperoxia.

Our findings also suggest that treatment with TNF/C and IL-1 may protect against hyperoxia without increasing lung antioxidant enzyme activities. Lung superoxide dismutase, glutathione peroxidase, glutathione reductase, glucose-6-phosphate dehydrogenase, or catalase activities were not increased in rats injected with both cytokines as compared with saline-injected rats that were simultaneously exposed to hyperoxia for $52 \mathrm{~h}$. In contrast, protection against hyperoxia achieved by pretreatment with endotoxin is associated with increases in lung superoxide dismutase, catalase, and glutathione peroxidase activities (1). In lieu of specific local changes in lung antioxidant levels, these 

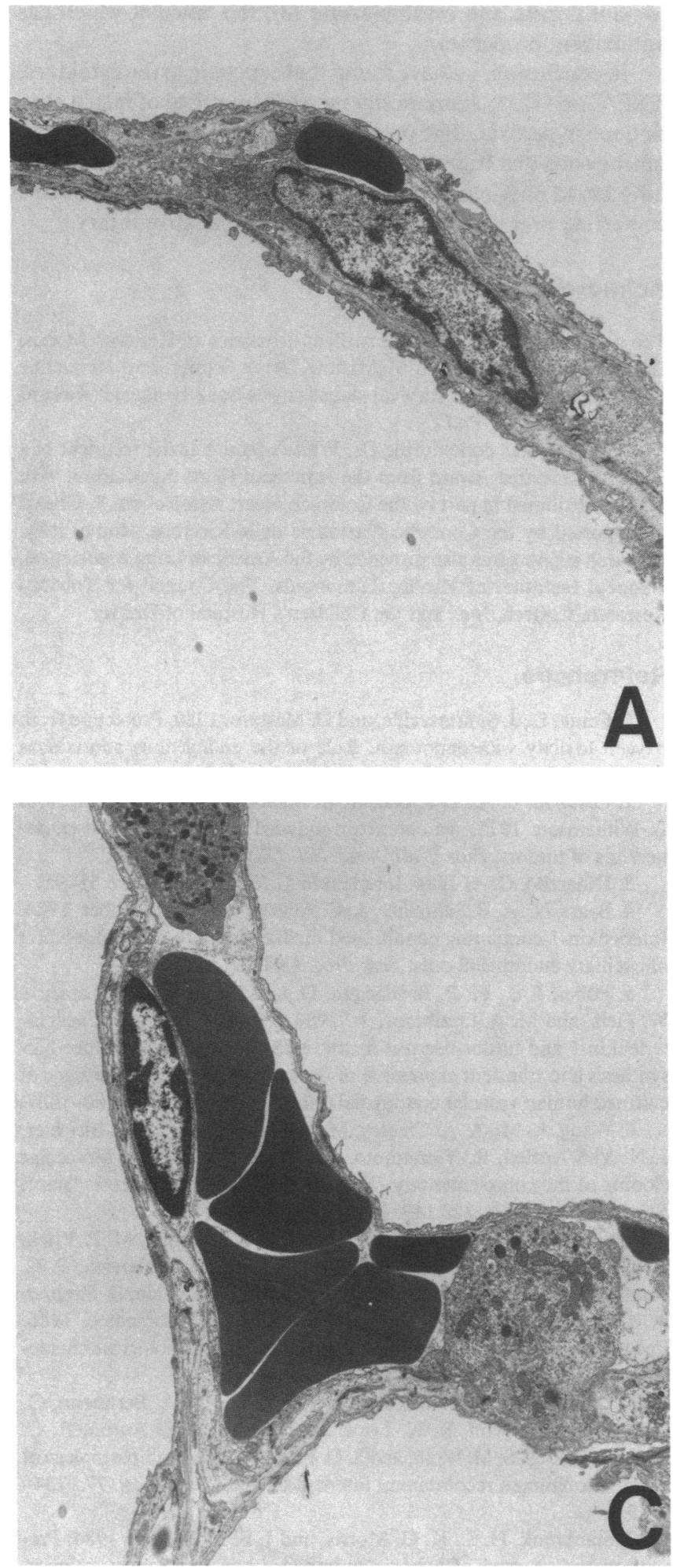

Figure 2. Ultrastructure of lungs from rats exposed to hyperoxia for 52 h. (A) Lungs from TNF/C + IL-1-treated rats had normal thin alveolar septa. An intact endothelial cell lined a capillary lumen that contained a red blood cell. (B) Lungs from saline-treated rats had markedly thickened alveolar septa due to interstitial fluid accumulation. Dissection of fluid distended and disrupted intracellular and extracellular compartments. $(C)$ Lungs from saline-treated rats also
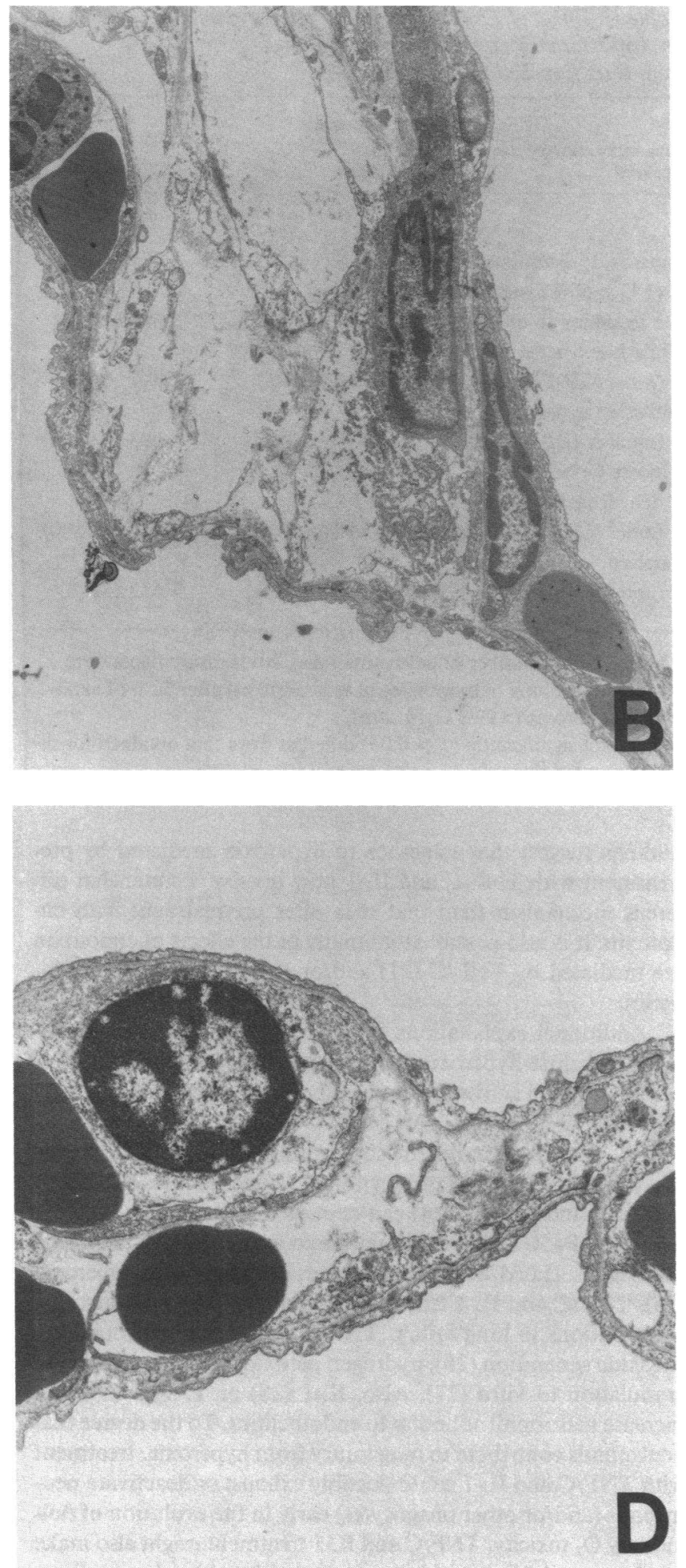

showed congestion of alveolar capillaries and sludging of red blood cells. Inflammatory cells were also present within the lumen. $(D)$ Lungs from saline-treated rats also manifested endothelial cell damage that consisted of swelling of endoplasmic reticulum and intracellular edema. Disruption of the capillary wall was seen with extravasation of fluid and red blood cells. ( $A$ and $B \times 3,800, C \times 4,700 ; D \times 9,100$ ). 
Table II. Effect of TNF/C and IL-1 Pretreatment on Antioxidant Enzyme Activities of Lungs from Rats Exposed to Hyperoxia

\begin{tabular}{lll}
\hline $\begin{array}{l}\text { Lung antioxidant enzyme } \\
\text { measured }\end{array}$ & Pretreatment \\
\cline { 2 - 3 } & Saline & TNF/C and IL-1 \\
\hline & U/right lung & U/right lung
\end{tabular}

Superoxide dismutase

( $1 \mathrm{U}=50 \%$ cytochrome

$c$ reduction inhibition)

$$
436 \pm 37(6)^{*}
$$

$466 \pm 12(6)^{\ddagger}$

Glutathione peroxidase (nmol NADPH/min)

$10.6 \pm 0.3(6)$

$10.2 \pm 0.7(6)^{\ddagger}$

Glutathione reductase

(nmol NADPH/min)

$1.99 \pm 0.10(6)$

$1.93 \pm 0.09(6)^{\ddagger}$

Glucose-6-phosphate

dehydrogenase

(nmol NADPH/min)

Catalase

( $\mu \mathrm{mol} \mathrm{H} \mathrm{H}_{2} \mathrm{O}_{2} / \mathrm{min}$ )

$3.98 \pm 0.32(6)$

$3.34 \pm 0.25(6)^{\ddagger}$

$1,758 \pm 65(6)$

$1,637 \pm 51(6)^{\ddagger}$

* Mean \pm SEM (number of determinations). All measurements were made on right lung homogenates of rats sacrificed after $52 \mathrm{~h}$ of exposure to hyperoxia ( $\left.>99 \% \mathrm{O}_{2}, 1 \mathrm{~atm}\right)$.

₹ Value not significantly $(P>0.05)$ different from that obtained for saline-pretreated rats.

findings suggest that tolerance to hyperoxia mediated by pretreatment with TNF/C and IL-1 may involve a somewhat different mechanism than that seen after pretreatment with endotoxin. It is also possible that many of the effects of endotoxin are mediated by TNF/C (21) and/or IL-1, but by different kinetics.

Additional explanations for TNF/C + IL-1-mediated protection against hyperoxia include that oxidant formation, inflammatory cell activation, and/or the acute phase response may be altered in lungs of TNF/C + IL-1-treated rats. For example, TNF/C and IL-1 treatment could diminish oxidant injury by decreasing microsomal production of $\mathrm{O}_{2}$ metabolites (22). Both IL-1 (23) and TNF/C (24) can depress hepatic microsomal cytochrome P450 activity, and failure to induce lung cytochrome $\mathrm{P} 450$ is associated with increased survival of mice in hyperoxia (25). TNF/C and IL-1 treatment could also modify neutrophil contributions to lung injury. TNF/C stimulates neutrophil superoxide generation (26), hydrogen peroxide formation, and degranulation in vitro (27). Also, IL-1 (28) or TNF/C (29) can increase neutrophil adhesion to endothelium. To the degree that neutrophils contribute to lung injury from hyperoxia, treatment with TNF/C and IL-1 could possibly exhaust or deactivate neutrophils (and/or other phagocytes) early in the evolution of pulmonary $\mathrm{O}_{2}$ toxicity. TNF/C and IL-1 treatment might also make less iron available to oxidants generated by either lung cells or phagocytes. IL-1 treatment could increase lactoferrin release from neutrophils, decrease serum iron, and increase hepatic iron sequestration $(3,8)$. Decreased iron in lung may be important by decreasing production of more toxic hydroxyl radicals from hydrogen peroxide and superoxide anion (30). Cytokines may also contribute to improved survival in hyperoxia by acting as growth factors that promote more rapid replacement of damaged cells $(4,31)$. Finally, IL-1 treatment has radioprotective effects (32) and also induces release of acute phase proteins, including $\alpha$-1-antitrypsin and ceruloplasmin (3), the latter of which has antioxidant properties.

In conclusion, we have found that exposure to the cytokines, TNF/C and IL-1, dramatically increased survival of rats in continuous hyperoxia. The results indicate that endotoxemia and other events that trigger release of these cytokine mediators may have broad physiologic consequences that involve mechanisms conferring protection against subsequent oxidative injury.

\section{Acknowledgment}

The authors acknowledge the excellent assistance of Kenneth Morris, Gary Mierau, Ph.D., Susan McMahon, Derek Schrier, and Jacqueline Borenstein. Analyses of survival statistics was done by Russel Rickard and Gary O. Zerbe, Ph.D.

This work was done during Dr. White's tenure as the recipient of a Clinician-Scientist Award from the American Heart Association, with funds contributed in part by the Colorado Heart Association. P. Ghezzi is supported by the Consiglio Nazionale delle Ricerche, Rome, Italy. Research support was also provided by the American Lung Association, National Institutes of Health, Tambrands, The Council for Tobacco Research, Cortech, Inc., and the Children's Hospital of Denver.

\section{References}

1. Frank, L., J. Summerville, and D. Massaro. 1980. Protection from oxygen toxicity with endotoxin. Role of the endogenous antioxidant enzymes of the lung. J. Clin. Invest. 65:1104-1110.

2. Carswell, E. A., L. J. Old, R. L. Kassel, S. Green, N. Fiore, and B. Williamson. 1975. An endotoxin-induced serum factor that causes necrosis of tumors. Proc. Natl. Acad. Sci. USA. 72:3666-3670.

3. Dinarello, C. A. 1984. Interleukin-1. Rev. Infect. Dis. 6:51-95.

4. Byars, N., A. B. Schreiber, A. C. Allison, and F. Modabber. 1984. Interleukin-1-containing conditioned media stimulate the proliferation of capillary endothelial cells. Fed. Proc. 43:462. (Abstr.)

5. Pober, J. S., M. P. Bevilacqua, D. L. Mendrick, L. A. Lapierre, W. Fiers, and M. A. Gimbrone, Jr. 1986. Two distinct monokines, interleukin 1 and tumor necrosis factor, each independently induce biosynthesis and transient expression of the same antigen on the surface of cultured human vascular endothelial cells. J. Immunol. 136:1680-1687.

6. Wang, A. M., A. A. Creasey, M. B. Ladner, L. S. Lin, J. Strickler, J. N. Van Arsdell, R. Yamamoto, and D. F. Mark. 1985. Molecular cloning of the complementary DNA for human tumor necrosis factor. Science (Wash. DC). 228:149-154.

7. Gubler, U., A. O. Chua, A. S. Stern, C. P. Hellman, M. P. Vitek, T. M. Dechiara, W. R. Benjamin, K. J. Collier, M. Dukovich, P. C. Familletti, C. Fiedler-Nagy, J. Jenson, K. Kaffka, P. L. Kilian, D. Stremlo, B. H. Wittreich, D. Woehle, S. B. Mizel, and P. T. Lomedico. 1986. Recombinant human interleukin 1:purification and biological characterization. J. Immunol. 136:2492-2497.

8. Dinarello, C. A., J. G. Cannon, J. W. Mier, H. A. Bernheim, G. LoPreste, D. L. Lynn, R. N. Love, A. C. Webb, P. E. Auron, R. C. Reuben, A. Rich, S. M. Wolff, and S. D. Putney. 1986. Multiple biological activities of human recombinant interleukin 1. J. Clin. Invest. 77:17341739.

9. Stanbrook, H. S., K. G. Morris, and I. F. McMurtry. 1984. Prevention and reversal of hypoxic pulmonary hypertension by calcium antagonists. Am. Rev. Respir. Dis. 130:81-85.

10. Crapo, J. D., B. E. Barry, H. A. Foscue, and J. Shelburne. 1980. Structural and biochemical changes in rat lungs occurring during exposures to lethal and adaptive doses of oxygen. Am. Rev. Respir. Dis. 122:123-143.

11. Adams, J. D., Jr., B. H. Lauterburg, and J. R. Mitchell. 1984. Plasma glutathione and glutathione disulfide in the rat: regulation and response to oxidative stress. J. Pharm. Exp. Ther. 237:749-754.

12. Crapo, J. D., J. M. McCord, and I. Fridovich. 1978. Preparation and assay of superoxide dismutases. Methods. Enzymol. 53:382-393. 
13. Beutler, E. 1975. Red cell metabolism. A Manual of Biochemical Methods. Grune and Stratton, New York. 1-160.

14. Bergmeyer, H. U. 1955. Zur messung von katalase-aktivataten. Biochem. Z. 327:255-258.

15. Steel, R. G. D., and J. H. Torrie. 1960. Principles and Procedures of Statistics. McGraw-Hill Book Company, Inc., New York, 1-481.

16. Kaplan, E. L., and P. Meier. 1958. Nonparametric estimation from incomplete observations. J. Am. Stat. Assoc. 53:457-481.

17. Peto, R., M. C. Pike, P. Armitage, N. E. Breslow, D. R. Cox, S. V. Howard, N. Mantel, K. McPherson, J. Peto, and P. G. Smith. 1977. Design analysis of randomized clinical trials requiring prolonged observation of each patient. Part 2. Analysis and examples. Br. J. Cancer. 35: 1-39.

18. Einot, I., and K. R. Gabriel. 1975. A study of the power of several methods of multiple comparisons. J. Am. Stat. Assoc. 70:574-583.

19. Jones, R., W. M. Zapol, and L. Reid. 1984. Pulmonary artery remodeling and pulmonary hypertension after exposure to hyperoxia for 7 days. Am. J. Pathol. 117:273-285.

20. White, C. W., R. F. Mimmack, and J. E. Repine. 1986. Accumulation of lung tissue oxidized glutathione (GSSG) as a marker of oxidant induced lung injury. Chest. 89:111S-113S.

21. Beutler, B., N. Krochin, I. W. Milsark, C. Luedke, and A. Cerami. 1986. Control of cachectin (tumor necrosis factor) synthesis: mechanisms of endotoxin resistance. Science (Wash. DC). 232:977-980.

22. Turrens, J. F., B. A. Freeman, and J. D. Crapo. 1982. Hyperoxia increases $\mathrm{H}_{2} \mathrm{O}_{2}$ release by lung mitochondria and microsomes. Arch. Biochem. Biophys. 217:411-421.

23. Ghezzi, P., B. Saccardo, P. Villa, V. Rossi, M. Bianchi, and C. A. Dinarello. 1986. Role of interleukin-1 in the depression of liver drug metabolism by endotoxin. Infect. Immun. 54:837-840.
24. Ghezzi, P., B. Saccardo, and M. Bianchi. 1986. Recombinant tumor necrosis factor depresses cytochrome P450-dependent microsomal drug metabolism in mice. Biochem. Biophys. Res. Commun. 136:316321.

25. Gonder, J. C., R. A. Proctor, and J. A. Will. 1985. Genetic differences in oxygen toxicity are correlated with cytochrome P-450 inducibility. Proc. Natl. Acad. Sci. USA. 82:6315-6319.

26. Tsujimoto, M., S. Yokota, J. Vilcek, and G. Weissmann. 1986 Tumor necrosis factor provokes superoxide anion generation from neutrophils. Biochem. Biophys. Res. Commun. 137:1094-1100.

27. Klebanoff, S. J., M. A. Vadas, J. M. Harlan, L. H. Sparks, J. R. Gamble, J. M. Agosti, and A. M. Waltersdorph. 1986. Stimulation of neutrophils by tumor necrosis factor. J. Immunol. 136:4220-4225.

28. Bevilacqua, M. P., J. S. Pober, M. E. Wheeler, R. S. Cotran, and M. A. Gimbrone, Jr. 1985. Interleukin-1 acts on cultured human vascular endothelium to increase the adhesion of polymorphonuclear leukocytes, monocytes, and related leukocyte cell lines. J. Clin. Invest. 76:20032011.

29. Gamble, J. R., J. M. Harlan, S. J. Klebanoff, and M. A. Vadas. 1985. Stimulation of the adherence of neutrophils to umbilical vein endothelium by human recombinant tumor necrosis factor. Proc. Natl. Acad. Sci. USA. 82:8667-8671.

30. Repine, J. E., R. B. Fox, and E. M. Berger. 1981. Hydrogen peroxide kills Staphylococcus aureus by reacting with staphylococcal iron to form hydroxyl radical. J. Biol. Chem. 256:7094-7096.

31. Sugarman, B. J., B. B. Aggarwal, P. E. Hass, I. S. Figari, M. A. Palladino, Jr., and H. M. Shepard. 1985. Recombinant human tumor necrosis factor- $\alpha$ : effects on proliferation of normal and transformed cells in vitro. Science (Wash. DC). 230:943-945.

32. Neta, R., S. Douches, and J. J. Oppenheim. 1986. Interleukin-1 is a radioprotector. J. Immunol. 136:2483-2485. 